\title{
Agricultura e desastres no sul de Santa Catarina $(1974-2004)^{1}$
}

\author{
Agriculture and disasters in the south of Santa Catarina state (1974-2004) \\ Agricultura y desastres en el sur de Santa Catarina (1974-2004)
}

Alfredo Ricardo Silva Lopes*

\section{Resumo}

Este trabalho tem por objetivo observar a relação entre os seres humanos e $\mathrm{o}$ ambiente na produção agrícola no sul de Santa Catarina, Brasil, que nos últimos quarenta anos potencializou a ocorrência de desastres. Nessa região, constantemente atingida por enchentes, as áreas alagáveis foram utilizadas para o plantio de arroz pré-germinado irrigado. Dessa forma, ao longo dos últimos anos, as áreas que absorviam grande parte da água da chuva passaram a ser protegidas da ação das enchentes, que seguiram para zonas que estavam sendo povoadas. A pesquisa sobre a produção dos desastres elucida uma gama de percepções e ações sobre o mundo natural, que vêm à tona nos momentos em que as forças da natureza suplantam a capacidade de intervenção humana.

Palavras-chave: Desastres socioambientais. Agricultura. Sul do estado de Santa Catarina.

\section{Introdução}

O presente trabalho discute a implementação do modelo de produção agrícola baseado no pacote aplicado pela Revolução Verde e sua relação com a potencialização das enchentes no sul de Santa Catarina. Desta forma, este artigo elucida a relação entre degradação ambiental e desastres na prática de uma agricultura pautada pelo modelo industrial de produção para o mercado.

Ao longo dos últimos 250 mil anos período em que surgiu o Homo sapiens - a experiência com as intempéries climáticas ofereceu diversos condicionantes para a espécie. Entretanto, foi apenas há $10 \mathrm{mil}$ anos, no Holoceno, após a última grande glacia-

Doutor em História pela Universidade Federal de
Santa Catarina. Historiador e professor na Univer-
sidade Federal de Mato Grosso do Sul, campus do
Pantanal. E-mail: alfredorsl@gmail.com

Recebido em 12/02/2016 - Aprovado em 28/03/2016 http://dx.doi.org/10.5335/hdtv.16n.1.6266 
ção, que a espécie humana encontrou condições adequadas para sua contínua e acentuada reprodução, o que a colocou no topo de quase todas as cadeias tróficas.

Foi ao longo do Holoceno, com a diminuição da variabilidade do clima, que o padrão de normalidade climática começou a balizar o significado dos desastres que chega até o século XX. No momento em que a escala e o impacto das intempéries tornou-se relativamente menor, a noção de normalidade teve sua amplitude diminuída. O desastre, notadamente de origem natural, passou a ser encarado como um momento de excepcionalidade, mesmo em uma realidade na qual o mundo natural impunha severas condições à existência humana. Curiosamente, um dos elementos centrais para a melhoria das condições de subsistência da espécie humana foi o desenvolvimento da agricultura.

A relativa estabilização da temperatura do planeta e a redução das atividades vulcânicas ofereceram aos seres humanos uma possibilidade inalcançada até hoje por qualquer outra espécie: produzir meios de transformar as dinâmicas naturais do planeta (CRUTZEN; STEFFEN, 2003). O geólogo alemão Reinhold Leinfelder (2013) defende o Antropoceno como uma hipótese científica baseada no pressuposto de que a humanidade recentemente tornou-se um condicionante para as transformações globais na circulação de água, no clima, na produtividade biológica, na biodiversidade, nos ciclos biogeoquímicos, nos padrões de sedimentação e na utilização global de terras e mares.

Desta forma, o mundo não poderia mais ser caracterizado por biomas - conjuntos naturais de habitats -, mas, sim, "antro- mas" - paisagens culturais, tais como florestas manejadas, terras agrícolas, pastagens e áreas urbanas (LEINFELDER, 2013, p. 10). A antropização das dinâmicas naturais da Terra teria começado 12 mil anos atrás com a Revolução Agrícola do Neolítico, mas só teria se constituído enquanto tal depois da utilização dos combustíveis fósseis na Revolução Industrial, que encontrou seu ponto de multiplicação com a "Grande Aceleração Industrial" depois da Segunda Guerra Mundial. Essa grande aceleração oferece uma oportunidade para comparar a aceleração dos processos naturais às acelerações sociais, tais como o aumento no PIB global, a financialização da economia, a barragem de rios, o uso de fertilizantes, a polinização artifical das flores, o crescimento da população urbana, o consumo de papel, a dispersão dos restaurantes fast foods, e as vendas de telefones celulares (LEINFELDER, 2013, p. 12).

Em Santa Catarina, essas transformações podem ser observadas nas mudanças realizadas na paisagem no intuito de aumentar a produção agrícola. Contudo, tais modificações alteram as dinâmicas naturais estabelecidas ao longo do tempo, e o aumento nas ocorrências e nos impactos dos desastres são analisados dentro dessa lógica. A catalogação das informações sobre os desastres começou naquele estado na década de 1980. Com essas informações, a geógrafa Maria Lúcia de Paula Herrmann e a equipe do Centro Universitário de Estudos e Pesquisas sobre Desastres da Universidade Federal de Santa Catarina, a pedido do governo estadual, confeccionaram a primeira edição do Atlas de desastres naturais do estado de Santa Catarina (2005). No volume, os rela- 
tórios de avaliação de danos enviados pelas prefeituras mostram que, de 1980 a 2004,

[...] foram totalizadas nos municípios catarinenses 1.299 ocorrências de inundações graduais, 555 de inundações bruscas, 140 de escorregamentos, 492 de estiagens, 342 de granizos, 502 de vendavais e 43 episódios de tornados (HERRMANN, 2005, p. 127).

O sul de Santa Catarina também assinalou essas ocorrências, no total, foram registrados 346 desastres, relatados exclusivamente como naturais. A maior parte está relacionada a inundações, que totalizam 257 ocorrências, dessas 179 foram graduais e 78 inundações bruscas (HERRMANN, 2005, p. 135).

Figura 1 - Mesorregião Sul Catarinense

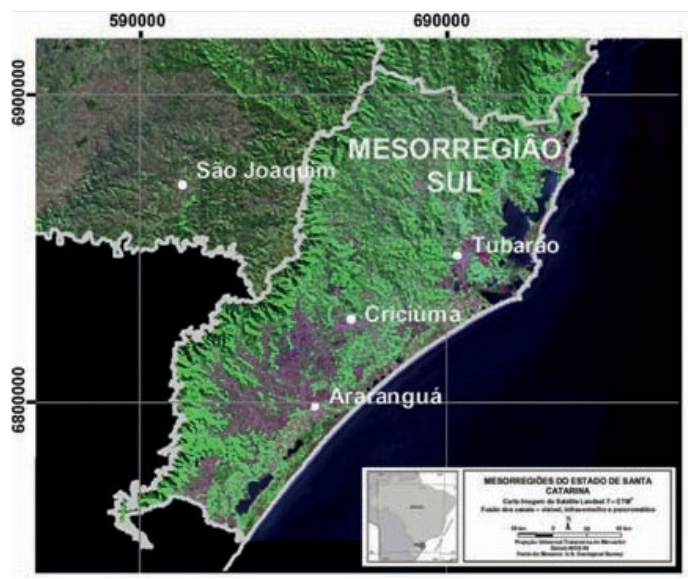

Fonte: adaptação de Herrmann (2005, p. 29).

A relevância do estudo dos desastres pela história na mesorregião não se dá apenas pela sua ocorrência, que leva em consideração as características únicas da região, delimitada no oeste pelas escarpas da Serra Geral e ao leste pelo oceano. Ao longo dos últimos 35 anos, o sul de Santa Catarina converteu-se na mesorregião com maior produtividade de arroz pré-germinado ir- rigado, o que contribuiu significativamente para a transformação da paisagem e potencializou a produção e o impacto dos desastres. Além dos desastres de origem natural que incidem sobre o sul catarinense, outros problemas ambientais também fazem parte do cotidiano da mesorregião, destacando-se os problemas relativos à poluição das águas devido à mineração e aos conflitos pelo uso da água devido à demanda hídrica do cultivo do arroz irrigado.

\section{A natureza do desastre}

O antropólogo Anthony Oliver-Smith (1999) esclarece que uma multiplicidade de acontecimentos pode ser enquadrada na categoria de análise desastre, entretanto, alguns elementos são centrais para sua categorização e compreensão. No tocante à variabilidade externa, referem-se a uma larga gama de objetos, fenômenos tidos como naturais e tecnológicos que geram ou desencadeiam tipos diferentes de impactos físicos. Enquadram-se nesse grupo desde desastres com impactos imediatos, como tornados, até desastres de contato prolongado, como exposição a toxinas.

Um dos pontos centrais para conceituação do desastre está em perceber sua variabilidade e complexidade. Oliver-Smith enfatiza que a variabilidade refere-se à imensa gama de fenômenos de caráter natural e tecnológico que geram "gatilhos" de desastres e produzem diferentes tipos de impactos físicos. A complexidade também está no centro da análise, em função de os desastres serem um ponto de intersecção de diversos processos e eventos de natureza social, am- 
biental, cultural, política, econômica, física e tecnológica. Nessa perspectiva, "os desastres são eventos totalizantes" (OLIVER-SMITH, 1999, p. 20), pois neles se desenrolam todas as dimensões da formação da estrutura social. O antropólogo enfatiza que o estudo dos desastres, além de analisar eventos específicos no tempo e no espaço, deve empreender uma abordagem processual que inclua o acontecimento desastre e as formas de lidar com ele dentro do seu contexto.

Caminhando para além da noção do desastre como um acontecimento único, este artigo se vale da história ambiental para entender as relações dos grupos humanos com o ambiente e vice-versa. O historiador ambiental brasileiro José Augusto Pádua (2010, p. 83) enfatiza que, até o século XVIII, as indagações humanas sobre o mundo natural giravam em torno de como a natureza influenciava a história humana, com o advento da Revolução Industrial e a diversificação das formas de apropriação dos recursos naturais, as indagações começaram a girar em outro sentido, pautadas em sua maioria na racionalidade do uso indiscriminado dos recursos naturais. O juízo de que a ação humana poderia interferir no meio natural, e até causar desastres, surgiu no final do século XIX, mas só se disseminou mundialmente no início da década de 1970 (PÁDUA, 2010, p. 86).

A história ambiental busca repensar o ser humano dentro do quadro mais amplo da história do planeta, por isso:

[...] o grande desafio teórico, no contexto da contemporaneidade, é pensar o ser humano na totalidade tensa e complexa de suas dimensões biológica e sociocultural (PÁDUA, 2010, p. 91-92).
Nesse caminho, a história ambiental procura formas menos dualistas de perceber e relacionar natureza e cultura, com o intuito de reconhecer a historicidade dos sistemas naturais.

Uma das premissas da história ambiental é a fuga de uma lógica estritamente antropocêntrica. Contudo, balizar a análise na fuga da preponderância dos seres humanos não significa o seu aviltamento frente à magnificência natural. Essa preocupação da história ambiental surgiu antes da proposição do Antropoceno, argumento que não se pauta em um especismo, no qual seres humanos seriam a espécie mais importante do planeta, mas, sim, na proposição de que a ação humana pode interferir na dinâmica ecológica de outras tantas espécies.

O livro Natural disasters, cultural responses: case studies toward a global environmental history, organizado por Christof Mauch e Christian Pfister, reúne uma série de estudos de caso em diversos locais do globo, e no decorrer do presente trabalho tais casos serão levantados com o intuito de estabelecer analogias com os desastres registrados no sul de Santa Catarina. Na introdução da obra, o historiador ambiental Christof Mauch (2009, p. 3) lembra que a palavra "catástrofe" vem do grego, e refere-se às reviravoltas das tragédias que permitem o reestabelecimento de um equilíbrio moral. O historiador ainda sugere que as memórias dos desastres naturais, diferentemente das memórias de guerra, tem marcadamente vida curta, pois, assim que as águas voltam aos níveis normais, a mídia perde o interesse no desastre, também não existem associações de veteranos dos desastres e apenas uns poucos memoriais espalhados pelo mundo. 
Para Mauch (2009, p. 7), a força da contribuição dos historiadores nesse caso está na possibilidade de olhar para trás e aprender com o passado, porque pesquisadores de outras discipflinas raramente lidam com eventos de décadas passadas. Dessa forma, os historiadores têm muito a contribuir para o amadurecimento da perspectiva que tomou fôlego a partir da década de 1980, de que as catástrofes não são nunca "naturais" no sentido pleno do termo, em vez disso, as ocorrências devem ser entendidas como eventos naturais, culturais e sociais. Pois, de fato, a forma como os humanos lidam com as catástrofes é largamente dependente de padrões culturais e sociais, valores, crenças religiosas, instituições políticas e estruturas econômicas que mudam ao longo do tempo.

Os trabalhos da historiadora ambiental Lise Sedrez sobre as enchentes na década de 1960 no Rio de Janeiro são pioneiros ao unir história ambiental e história oral para compreender o alcance das políticas públicas (MAIA; SEDREZ, 2011). Amplamente sustentada na história social, Sedrez destaca a ação do Estado e as expectativas da população; em seus trabalhos, ela mostra como a sensação de segurança criada pela vida em sociedade é destruída pela ocorrência do desastre, ocorrência que surge como resultado de uma mistura perigosa:

[...] ocupação de áreas pantanosas e/ou mangues com a diminuição da capacidade de absorção do solo, em uma área onde a chuva é parte do ecossistema num processo de urbanização desgovernado (SEDREZ, 2013, p. 253).
Em História ambiental e desastres: encontros entre política, tecnologia e sociedade, o historiador ambiental Jó Klanovicz (2013) destaca a função do desastre para trazer a discussão renovada acerca do retorno do acontecimento na história, o que necessariamente traz à tona as discussões sobre série, longa duração, caos, continuidade ou ruptura. Ao analisar a explosão do reator 4 da "Usina Nuclear de Tchornobyl”, em 1986, Klanovicz (2013, p. 300) destaca que uma das grandes contribuições da história ambiental é retomar o papel da discussão política na história, e também enfatiza o papel que o Estado deveria exercer, especialmente para proteger os cidadãos em uma sociedade industrial que universalizou de forma desigual os riscos da produção de riqueza. Olhando estritamente para o desastre tecnológico, aquele produzido essencialmente pela ação humana, Klanovicz também emprega o conceito de sociedade de risco, proposto por Ulrich Beck e debatido ao longo deste trabalho, para defender a necessidade de uma análise mais plural que incida sobre os desastres.

O conceito de Ulrich Beck, que surge em 1970, analisa a eclosão de desastres como a expressão social da vulnerabilidade produzida pela sociedade industrial. Nesse modelo, a noção de sociedade de risco (BECK, 2010) confere força à ideia de que os riscos são produzidos socialmente e, também, são resultado da profunda antropização dos ambientes. Esse paradigma descartou a ideia simplista de que os desastres tidos como naturais causavam impactos nas sociedades humanas, fortalecendo o entendimento de que o processo de formação das vulnerabilidades é social. 


\section{A produção do desastre}

O sul catarinense constitui-se de uma superfície de $8.823,5 \mathrm{~km}^{2}$, o que corresponde a $9,24 \%$ da área total do estado de Santa Catarina, com aproximadamente 850.000 habitantes (IBGE, 2010). Atualmente, a região abrange 43 municípios. Das quatro bacias hidrográficas existentes na região, serão analisadas três: Bacia Hidrográfica do Rio Tubarão, Bacia Hidrográfica do Rio Araranguá e Bacia Hidrográfica do Rio Mampituba.

A região sul do estado de Santa Catarina apresenta uma dinâmica atmosférica bem diversificada, principalmente por causa da chegada das massas polares, que potencializam a gênese de outros sistemas atmosféricos, sendo a frente fria o mais comum deles. As condições de tempo que incidem sobre o sul de Santa Catarina também são modificadas à medida que os sistemas avançam sobre o território, especialmente em virtude da distância das escarpas da Serra Geral e da proximidade do Atlântico.

Esse emaranhado de modificações produz microclimas com diferentes características ao longo de toda a região. A influência do relevo nos sistemas atmosféricos se dá à medida que a amplitude altimétrica do relevo consegue modificar a compressão ou descompressão adiabática de um sistema a ponto de produzir totais pluviais de maior ou menor grau, diretamente relacionados à exposição ao terreno (MONTEIRO, 2007, p. 25).
Figura 2 - Imagem de satélite do dia 21 de novembro de 2006, às 13:10 UTC, com muitas nuvens no litoral, Vale do Itajaí e na maior parte do planalto de Santa Catarina e nas encostas sul da Serra Geral (circulação marítima)

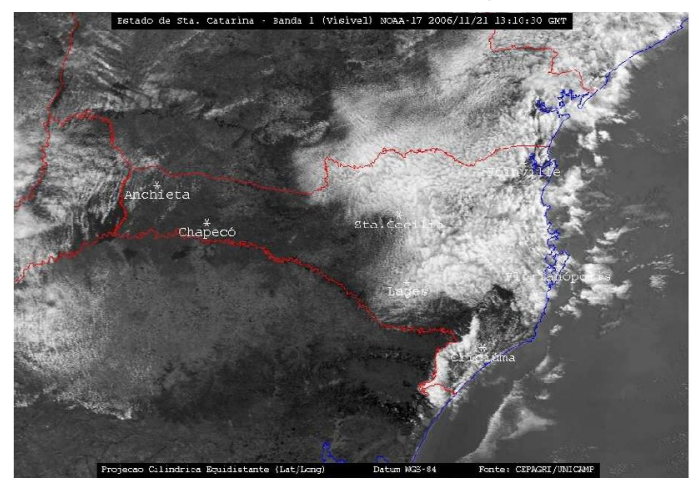

Fonte: Monteiro (2007, p. 76).

As variações altimétricas produzidas pelo relevo na região não chegam a impedir o deslocamento dos sistemas atmosféricos que incidem sobre o sul catarinense, mas transforma-os deixando-os, em certa medida, mais fracos ou mais ativos. Essa interferência é representada pelas elevações das escarpas da Serra Geral a 1.000 metros de altitude, que serve de barreira aos sistemas que incidem na região via litoral. A instabilidade surge como resultado do esfriamento do ar, na proporção de $1^{\circ} \mathrm{C}$ para cada 100 metros, o que colabora para o aumento da intensidade da precipitação.

Outra característica marcante na região sul são os leques aluviais. Esses depósitos fluviais têm a aparência de um leque, que se desenvolve a partir do sopé de uma elevação montanhosa, de onde se expande, do ponto de origem, espalhando-se à jusante do canal. Os leques fazem parte de um sistema complexo de erosão e deposição que, por meio do aumento da vasão do canal com as águas da chuva, passa a transferir 
detritos a uma zona mais baixa, em que se produz a sedimentação. Segundo a geóloga Gerusa Maria Duarte (1993, p. 95), uma das características marcantes dos leques aluviais é delimitação de uma zona em que predomina a erosão e outra em que predomina a deposição. Desse modo, o tipo de associação entre o "bloqueio" produzido pelo relevo e o aumento na vazão de detritos dos leques aluviais depende diretamente da existência de cobertura florestal para diminuir a quantidade e a força dos detritos carregados nos momentos de enchente.

A composição das florestas na região foi alterada drasticamente. Inserida no bioma Mata Atlântica, obedece às seguintes configurações: a Floresta de Restinga estendia-se pela planície costeira, fixada nos solos mais arenosos, um exemplo da flora seria a figueira-de-folha-miúda (Ficus organensis); a Floresta Paludosa, que é também uma forma de Floresta Ombrófila Densa de Encosta, está localizada nos solos turfosos das várzeas das lagoas; a Floresta Submontana pode ser encontrada nas cabeceiras de drenagem com solos profundos, em que a canela-preta (Ocotea catharinensis) e o palmito (Euterpe edulis) se destacam; a Floresta Montana é encontrada nas escarpas planálticas, normalmente com altitude superior a 400 metros, e o destaque arbóreo é da família das mirtáceas (CAMPANILI; SCHAFFER, 2010; VIBRANS et al., 2013).

Na bacia do Araranguá, por exemplo, a geógrafa Nadia Alexandre explica que os remanescentes de floresta atualmente são apenas encontrados nas áreas íngremes das encostas da Serra Geral. A cobertura vegetal nativa do sul catarinense:
[...] era quase na totalidade, representada por Floresta Ombrófila Densa, sendo que se destacavam como espécies econômicas: peroba-vermelha, baguaçu, canela-preta, aguaí, bicuíba, cedro, ipê-amarelo e o palmiteiro. Essa vegetação originalmente cobria quase a totalidade da bacia do Rio Araranguá estendendo-se até às margens dos cursos d'água formando a floresta ou vegetação ciliar (ALEXANDRE, 2000, p. 54).

Desta forma, foram vários os processos que contribuíram para a devastação das matas. A agropecuária teve papel basilar no processo, depois a progressiva utilização da lenha como fonte de energia para a urbanização, para as olarias e estufas de fumo e, por fim, com a implantação do Programa Nacional para Aproveitamento de Várzeas Irrigáveis (Provárzeas), as florestas ficaram restritas aos terrenos mais íngremes e de difícil acesso (VIBRANS et al., 2013).

\section{Agricultura desastrosa}

O desenvolvimento da agricultura no sul de Santa Catarina não ocorreu sempre voltado para a prática do arroz. No início do processo de instalação dos imigrantes lusitanos e seus descendentes, a agricultura em pequenos módulos policultores era a base para fixação dos colonos à terra. Os gêneros mais produzidos eram a mandioca, o arroz, a cana-de-açúcar, o milho, o algodão e a banana. Os impactos causados por essas culturas eram relativamente baixos, em virtude tanto do local em que os produtos eram plantados quanto da dimensão da área para o cultivo.

A ocupação europeia ou eurodescendente ao longo dos rios foi empreendida 
desde a fundação de Antônio dos Anjos de Laguna, a atual Laguna, em 29 de julho de 1676. Conforme as leis provinciais de Santa Catarina, publicadas em 1840, a instalação dos colonos ao longo dos rios tinha dois principais objetivos: estabelecer os produtores agrícolas perto de fluxos de água e facilitar a proteção desses indivíduos contra os indígenas agressivos que foram paulatinamente empurrados para o oeste (SELAU, 2006).

A segunda onda de imigrantes europeus que se estabeleceram no sul de Santa Catarina, no final do século XIX, foi predominantemente de indivíduos originários da península itálica. Esse grupo seguiu para oeste, cada vez mais perto das encostas da Serra Geral, em função de os espaços litorâneos terem sido ocupados pelos lusodescendentes. Nessa perspectiva, os novos imigrantes tornavam-se mais vulneráveis ao risco das enchentes à medida que se estabeleciam nas cotas sujeitas às enchentes bruscas, pois as localidades recebiam uma vasão de água que carregava mais energia. Diferente da região litorânea, na qual as enchentes graduais, mais lentas, são mais comuns.

Como já mencionado, parece estranho tratar sobre o caráter desastroso da agricultura, uma vez que foi justamente a agricultura que possibilitou à espécie humana estabelecer melhores condições de sobrevivência. No entanto, é preciso considerar que a agricultura desenvolvida atualmente já não é mais a mesma desenvolvida do começo do Neolítico até a Revolução Industrial.

A rizicultura torna-se emblemática nessa perspectiva, em razão das modificações que incidiram sobre a prática ao longo de todo o século XX. Como explica a historiado- ra Juliana Brocca Presa (2011), que analisou as transformações na vida dos rizicultores da bacia do Araranguá após a implantação do Provárzeas na década de 1980, uma das razões para que o programa tivesse êxito era a afinidade que os descendentes dos imigrantes já tinham com a cultura; outro ponto, era o contínuo e sistemático auxílio recebido pelos extensionistas da Empresa de Pesquisa Agropecuária e Extensão Rural de Santa Catarina e os financiamentos dos governos federal e estadual, na esteira da Revolução Verde, e, ainda, a possibilidade de escoar a produção via a recém-pavimentada BR-101.

Uma das necessidades básicas para a implantação do programa era a sistematização das várzeas. Esse processo, que significava o nivelamento e a transformação do solo, mudou tanto a paisagem quanto a dinâmica hídrica da região. O historiador ambiental David Blackbourn (2004), ao analisar a dominação da natureza na Prússia de Frederico, o Grande (1740-1786), destaca a busca pelo uso racional da poderosa natureza como motivo para drenagem dos pântanos na planície norte da atual Alemanha. Da mesma forma que na Alemanha do século XVIII, no sul de Santa Catarina, a dominação das várzeas era legitimada pelo uso racional da natureza, o racional nesses casos pode ser explicado pela transformação do meio natural para melhoramento da produção agrícola. Essa razão universalizante, entendida enquanto fruto do engenho humano para vencer as adversidades da natureza, não conseguiu dar conta das consequências que as drenagens produziram.

No caso do império prussiano, a necessidade da intervenção era também baseada 
na busca por novas terras agriculturáveis e na destruição dos pântanos formadores de miasmas. ${ }^{2}$ Blackbourn (2004) esclarece que alguns constantes desastres eram largamente evitados por essas terras "sem uso", que, após a drenagem, tiveram seu potencial erosivo aumentado pelas constantes enchentes, e dois séculos depois da transformação da paisagem, não há ainda solução segura para a região.

Presa (2011, p. 29) explica que, na primeira metade do século $\mathrm{XX}, \mathrm{o}$ arroz era uma cultura secundária na região, inicialmente, era o milho que recebia as melhores terras, pelo fato de ser uma cultura versátil, usada para alimentação humana e animal. Dessa Forma, o milho era plantado na várzea, nos terrenos mais baixos e mais férteis, e o arroz no espigão, terrenos mais altos e menos férteis. A explicação apontada pela autora para a primeira mudança no regime de plantio do arroz, com a troca da várzea pelo espigão, vem da experiência dos agricultores com as enchentes, pois com o alagamento das várzeas, as perdas de milho tendiam a ser significativas. Por causa da importância do milho, ele começou a ser plantado nas partes mais altas e, ainda, já que nem sempre as águas da enchente destruíam toda a plantação de arroz, os agricultores perceberam que a produtividade e a qualidade do arroz plantado na várzea tinham melhorado.

Segundo Mazoyer e Roudart (2010), a revolução agrícola contemporânea teve seu início no decorrer da primeira metade do século XX, mas foi só a partir de 1950 que conseguiu progredir vigorosamente nos países desenvolvidos e em alguns setores limitados dos países em desenvolvimento. Dentre suas características, estão:
[...] elevada motorização-mecanização, seleção de variedades de plantas e de raças de animais com forte potencial de rendimento, ampla utilização de fertilizantes, dos alimentos concentrados para o gado e produtos de tratamento das plantas e animais domésticos (2010, p. 27).

Os autores afirmam que, no encalço do desenvolvimento agrícola, logo veio a queda dos preços dos produtos, pois os ganhos de produtividade foram tão rápidos e tão elevados durante a Revolução Verde que ultrapassaram os da indústria e do setor de serviços. A forte queda nos preços dos produtos bloqueou o desenvolvimento dos estabelecimentos agrícolas menos favorecidos, e tal processo forneceu para os grandes centros industriais o contingente populacional que não encontrava mais no meio rural as condições de sobrevivência.

Sobre a Revolução Verde, os engenheiros-agrônomos Mazoyer e Roudart explicam que:

[...] ainda nos países em desenvolvimento, a partir dos anos 1960, a revolução verde, uma variante da revolução agrícola desprovida de motorização-mecanização, desenvolveu-se muito mais amplamente. Baseada na seleção de variedades com bom rendimento potencial de arroz, milho, trigo, soja e outras grandes culturas de exportação, baseada também numa ampla utilização de fertilizantes químicos, dos produtos de tratamento e, eventualmente, em um eficaz controle da água de irrigação e da drenagem, a revolução verde foi adaptada pelos agricultores que eram capazes de adquirir esses novos meios de produção e nas regiões favorecidas, onde era possível de rentabilizá-los (2010, p. 28).

No contexto do pós-guerra, o sucesso do crédito rural, aliado à assistência técnica, 
econômica e social, propiciada pelos agentes de extensão, incentivou o então presidente da República, Juscelino Kubitschek, a realizar convênios com os Estados Unidos da América para expandir em todos os estados brasileiros os serviços de extensão rural nos moldes dos criados em Minas Gerais e São Paulo. Segundo Mauro Oliveira, de 1948 a 1968, estruturou-se o "período pedagógico-político da atividade extensionista" (1999, p. 98) da modernização agrícola no Brasil.

O sucesso da Revolução Verde em Santa Catarina está intimamente ligado à atuação do órgão estadual de extensão rural. Segundo Carvalho, Nodari e Nodari, no ano de 1957, foi criada a Associação de Crédito e Assistência Rural do Estado de Santa Catarina (Acaresc),

[...] que se caracterizava como uma associação civil, sem fins lucrativos, de direito jurídico privado, cujos recursos provinham das prefeituras conveniadas, do governo estadual e do governo federal (2009, p. 2763).

Os autores também enfatizam que, “desde o $1^{\circ}$ Relatório de Atividades da ACARESC, de 1957, é relatado que os agrotóxicos já eram usados em Santa Catarina" (2009, p. 2763). Nesse contexto, asseguram que a ação da extensão rural em Santa Catarina foi preponderante para o aumento brutal no uso de agrotóxicos, que em 1975 já chegava a $87 \%$ das propriedades rurais do estado (180 mil dos 206.505 mil estabelecimentos).

Presa enfatiza que não houve três formas diferentes de cultivo do arroz, mas:
O que houve foi uma modificação no método de cultivo do "espigão" para o sistema de cultivo sequeiro ou irrigado tradicional, por volta da década de 1950. Portanto, de fins de 1950 até fins de 1970, plantou-se da forma irrigada tradicional. Posteriormente, na década de 1980, o PROVÁRZEAS, a partir do incentivo ao aproveitamento de várzeas irrigáveis, desenvolveu dentro do sistema de cultivo irrigado um método baseado no uso de sementes pré-germinadas (2011, p. 96).

O Provárzeas foi elaborado em 1978, pelo governo de João B. Figueiredo, e oficializado pelo Decreto $n^{\circ} 86.146$, em 23 de junho de 1981, visando à utilização econômica das várzeas em todos os estados brasileiros, e elegendo os solos aluviais ou hidromórficos como a última fronteira para o desenvolvimento agrícola do país. Nesse caso, a parceria com o Departamento Nacional de Obras e Saneamento foi fundamental para o sucesso do projeto, pois, para o que o aproveitamento "racional" das várzeas tão defendido pelo projeto fosse executado pelos agricultores, as áreas destinadas deveriam ser "recuperadas", ou seja, niveladas e conectadas à rede fluvial (PRESA, 2011, p. 106).

O cultivo de arroz no sul catarinense, entre 1980 e 1987, teve um crescimento de área agriculturável de $140 \%$, “[...] sendo que o fator que mais contribuiu para essa expansão foi o uso sistematizado das várzeas no início dos anos 1980" (HADLICH et al., 1997, p. 73). Para que não reste dúvida sobre a contribuição do programa, "no mesmo período a área destinada ao fumo aumentou 26\%" (HADLICH et al., 1997, p. 73). Áreas extensas de várzeas - incluindo áreas do entorno da Lagoa de Sombrio, maior corpo de água doce do sul de Santa Catarina - eram ocupa- 
das pela cultura do arroz irrigado, sendo que nas duas culturas o uso de agrotóxicos é intenso e são raras as famílias que não utilizam esses produtos (HADLICH et al., 1997, p. 77).

O cultivo do arroz pré-germinado exige certas condições, para tanto, foi necessária a adoção de novas tecnologias para a sistematização do solo, para que o preparo de solo pudesse dar condições à inundação, ao uso de novas cultivares, à fertilização do solo, ao controle de pragas/fitopatologias e de plantas daninhas com lâmina de água e colheita mecanizada (PRESA, 2011, p. 116). Também, foi nesse momento que se difundiu o uso de biocidas e fertilizantes, popularmente conhecidos como agrotóxicos, o que possibilitou o controle de pragas até então invencíveis.

A historiadora Presa (2011, p. 135) elenca o uso de uma série de herbicidas, pois, após a modificação do cultivo para o sistema pré-germinado, houve maior incidência de plantas invasoras aquáticas. Ela cita como exemplos o Herbadox 500 e o Bi-hedonal, usados no momento de pós-emergência, quando o arroz era imerso em água, popularmente chamado de "benzedura".

Nesse contexto, Presa ainda explica que:

No início da década de 1980 as doses de aplicação de herbicidas eram altas, alguns tinham recomendações de até dez litros por hectare como é o caso do Satanil ou do Saturn (benthiocarb). Atualmente as recomendações para doses de herbicidas não chega a um litro por hectare; para o Ally (metsulfuron), a dose é de 3,3 gramas de produto para cada hectare (2011, p. 135).

Com a transformação da paisagem que a nova técnica agrícola promoveu no início da década de 1980, o geógrafo Luis Carlos Rosso afirma que, devido à elevada taxa de percolação, fluxo da água através do solo, "muito se subtraiu da reserva da Mata Atlântica presente em solos orgânicos (organossolos)", de modo que:

[...] hoje se encontram pequenas ilhas ou fragmentos daquela formação florestal sem a preocupação de se manter a reserva legal que deveriam compor a mata ciliar (ROSSO, 2007, p. 12).

Como se verifica na Tabela 1, tanto na microrregião que compreende a Associação de Municípios do Extremo Sul Catarinense (Amesc), no lado catarinense da Bacia do Mampituba e Bacia do Araranguá, quanto na Associação de Municípios da Região de Laguna (Amurel), na Bacia do Tubarão e no complexo lagunar, houve uma diminuição na área total agriculturável de 1966 a 1995, período que compreende os Censos Agropecuários de 1975, 1985 e 1995. Entretanto, no mesmo momento, a rizicultura passou a ocupar uma área cada vez maior nas duas regiões, seguida por um exponencial aumento de produtividade. Antes da implantação do Provárzeas, a produção na Amesc era de aproximadamente 36.792 toneladas por ano, já em 1995, a produção chega a 184.909, um valor cinco vezes mais alto. A microrregião da Amurel, apesar de ter uma produção menor que o extremo sul, quadruplicou sua produção de arroz no mesmo período. 
Tabela 1 - Rizicultura nas microrregiões da Amesc e da Amurel

\begin{tabular}{l|r|r|r}
\hline \multicolumn{1}{c|}{$\begin{array}{c}\text { Censo agropecuário - } \\
\text { Amesc }\end{array}$} & \multicolumn{1}{c|}{1975} & \multicolumn{1}{c|}{1985} & \multicolumn{1}{c}{1995} \\
\hline Área total (ha) & 190.656 & 178.284 & 161.854 \\
Área arroz (ha) & 19.413 & 23.977 & 36.067 \\
Arroz casca (t/ano) & 36.792 & 76.231 & 184.909 \\
Arroz grão, beneficiado & 2,0 & 321,0 & 859,4 \\
(t/ano) & 1.129 & 2.491 & 3.077 \\
Tratores & 1975 & 1985 & 1995 \\
Censo agropecuário - & & \\
Amurel & 297.758 & 305.673 & 282.097 \\
Área total (ha) & 6.018 & 11.928 & 10.077 \\
Área arroz (ha) & 12.111 & 37.198 & 41.932 \\
Arroz casca (t/ano) & 374,0 & 104,0 & 127,8 \\
$\begin{array}{l}\text { Arroz grão, beneficiado } \\
\text { (t/ano) }\end{array}$ & 413 & 1.693 & 2.145 \\
\hline \begin{tabular}{l} 
Tratores \\
\hline
\end{tabular}
\end{tabular}

Nota: municípios que compõem a Amesc: Araranguá, Balneário Arroio do Silva, Balneário Gaivota, Ermo, Jacinto Machado, Maracajá, Meleiro, Morro Grande, Passo de Torres, Praia Grande, Santa Rosa do Sul, São João do Sul, Sombrio, Timbé do Sul e Turvo. Municípios que compõem a Amurel: Armazém, Braço do Norte, Capivari de Baixo, Grão Pará, Gravatal, Imaruí, Imbituba, Jaguaruna, Laguna, Pedras Grandes, Pescaria Brava, Rio Fortuna, Sangão, Santa Rosa de Lima, São Ludgero, São Martinho, Treze de Maio, Tubarão.

Fonte: elaboração dos autores com base nos dados do Censo Agropecuário dos anos 1975, 1985 e 1995 (IBGE, 1976, 1986, 1996).

Como parte fundamental do projeto, a utilização racional de máquinas e implementos agrícolas era parte do pacote tecnológico financiado pelo governo federal, além do trabalho no plantio e colheita, a mecanização rural também foi necessária para a efetivação dos projetos de saneamento e drenagem e na manutenção dos terrenos. Pode-se perceber que na Amesc o número de máqui- nas dobrou a cada dez anos; na Amurel, a mecanização foi mais agressiva na primeira década, mas continuou em ritmo crescente.

No âmbito da criação de cooperativas para potencialização da comercialização, o programa também incentivou a criação de cooperativas para o beneficiamento do arroz em nível microrregional. Isso explica a diferença entre as 2 toneladas por ano de arroz beneficiadas antes do Provárzeas e as 859,4 toneladas por ano beneficiadas de 1984 a 1995. A relação inversa pode ser observada na microrregião da Amurel em virtude dessa descentralização regional do beneficiamento, à medida que a produção do extremo sul passa a encontrar guarida na própria região.

A sistematização do Provárzeas, a partir de 1981, transformou a demanda hídrica das bacias do Araranguá e do Mampituba, produzindo uma situação de constantes conflitos pelo uso da água. Em meados da década de 1990, o engenheiro-agrônomo Rene Kleveston (1997) analisou o consumo de água na bacia do Rio Araranguá e constatou que, de março a setembro, a média da demanda hídrica seria de $14 \mathrm{~m}^{3} / \mathrm{s}$, sendo $1,65 \mathrm{~m}^{3} / \mathrm{s}$ para consumo humano, $0,3 \mathrm{~m}^{3} / \mathrm{s}$ destinado ao uso industrial e $12 \mathrm{~m}^{3} / \mathrm{s}$ para a mineração. Já no período de outubro a fevereiro, momento também de maior média de precipitação do ano, a demanda por água chega a alcançar $57 \mathrm{~m}^{3} / \mathrm{s}$, sendo $43 \mathrm{~m}^{3} / \mathrm{s}$ destinados à atividade agrícola, os demais usos continuam com os mesmos valores.

A geógrafa Magda Eliz Portelli (1998) explica que o cultivo do arroz, predominantemente nas partes média e inferior da planície costeira, é o principal responsável pelo reafeiçoamento da planície. Com a constru- 
ção de novos canais para abastecimento e ampliação das canchas de arroz, "ocorre a descaracterização da morfologia típica dos leques aluviais, assim como o desaparecimento dos paleocanais, representados pelas sangas" (1998, p. 42).

Nesse sentindo, as terras utilizadas para o plantio de arroz têm sua capacidade de infiltração reduzida, em virtude do trabalho de sistematização realizado pelas máquinas. Cabe então aos canais de irrigação todo o esforço de drenar a água destinada à rizicultura e a água trazida pelas enchentes. A utilização predatória da vegetação e o uso inadequado do solo também colaboram para a erosão acelerada e a diminuição da fertilidade do solo, o que, por sua vez, contribui para o agravamento das enchentes e o assoreamento do leito dos rios.

\section{Consideracões finais}

Os diversos desastres que incidem sobre o sul de Santa Catarina não foram todos produzidos pela transformação das características naturais do sul de Santa Catarina, mas foram potencializados pela ação humana. Ainda, a interação dos desastres com o ambiente produziu efeitos, como o aumento da erosão do solo, que eram impensáveis para os implementadores dessas mudanças. A peculiar relação entre as dinâmicas atmosféricas e as encostas da Serra Geral, em interação com a planície que abriga os leques aluviais, naturalmente transforma a dinâmica das enchentes. Somadas a isso, as transformações na cobertura vegetal e o aumento populacional produzem um cenário ainda mais propenso à eclosão dos desastres.
O sociólogo alemão Ulrich Beck desenvolve o argumento de que, na sociedade de risco, o risco está presente em todos os setores do atual mundo globalizado. Beck define a sociedade de risco como aquela em que a aceitação dos riscos é essencial e anterior à produção de riqueza, diferente do modelo do início da Revolução Industrial, quando o risco surgia como consequência da produção de riqueza. Na sociedade de risco, a incerteza ofusca até mesmo o progresso científico-tecnológico, “[...] eles (os riscos) já não podem mais ser limitados geograficamente ou em função de grupos específicos" (BECK, 2010, p. 16).

Beck analisa a aliança entre capitalismo e desenvolvimento tecnológico, na formação de uma modernidade globalizada, radicalizada e tardia, conectada a uma mesma experiência mundial, em que o risco torna contraditória a noção do individualismo moderno, que socializa o perigo sem respeitar classe, gênero ou crenças. A agricultura desastrosa pode ser inscrita dentro da análise de Beck não apenas pelo risco que cada indivíduo corre ao consumir alimentos com agrotóxicos ou geneticamente modificados, mas, também, em virtude das transformações produzidas pelas implementações agrícolas da Revolução Verde.

No decorrer do século XX, o capitalismo industrial conseguiu instaurar uma era de dominação por todo o globo, as consequências dessa preponderância na forma de produzir também alcançaram a sociedade de massa. As transformações no sul de Santa Catarina mesclam-se às mudanças ambientais produzidas em escala global, os desastres nesses casos precisam ser entendidos 
como acontecimentos sintomáticos dentro de processos inscritos em uma duração que combina diversas temporalidades.

\section{Abstract}

The aim of this work is to observe the relationship between human beings and the surrounding environment in the agriculture in southern part of Santa Catarina State (Brazil). Those relationships have influenced the disasters occurence for the past 40 years. In that region, normally affected by floods, the wetlands have been used for pre-germinated irrigated rice crops. Thus, the areas that before absorved part of the rain waters, starts to be protected from the floods, and now the water flow in other directions, which includes some cities. The research about disasters production elucidates a large range of environmental perceptions and actions, which come up when nature supplants the human capacity of intervention.

Keywords: Socioenvironmental disasters. Agriculture. South of Santa Catarina State.

\section{Resumen}

El estudio tiene como objetivo observar la relación entre los seres humanos y el medio ambiente en la producción agrícola en el sur de Santa Catarina (Brasil), que en 40 años ha incrementado la ocurrencia de desastres. En esta región, que es constantemente golpeada por las inundaciones, los humedales se han utilizado para la plantación de arroz pre- -germinada irrigada. Por lo tanto, en los últimos años las áreas que absorben la mayor parte del agua de lluvia, han sido protegidos de la acción de las inundaciones que se dirigían a las zonas que se estaban pobladas. La investigación sobre la producción de desastres aclara una serie de percepciones y acciones sobre el mundo natural, que vienen a primer plano en momentos que las fuerzas de la naturaleza superan la capacidad de intervención humana.

Palabras clave: Desastres sociales y medioambientales. Agricultura. Sur de Santa Catarina.

\section{Notas}

1 Este trabalho faz parte da tese de doutorado Desastres socioambientais no sul de Santa Catarina (1974-2004), defendida no Programa de Pós-Graduação em História da Universidade Federal de Santa Catarina, com orientação da professora doutora Eunice Sueli Nodari.

2 Segundo a teoria dos miasmas, várias doenças teriam sua origem dos odores fétidos da matéria orgânica em decomposição.

\section{Referências}

ALEXANDRE, N. Z. Análise integrada da qualidade das águas da bacia do Rio Araranguá (SC). Dissertação (Mestrado em Geografia) - Programa de Pós-Graduação em Geografia, Universidade Federal de Santa Catarina, Centro de Filosofia e Ciências Humanas, Florianópolis, 2000.

BECK, U. Sociedade de Risco - rumo a uma outra modernidade. São Paulo: Editora 34, 2010.

BLACKBOURN, D. Conquest from barbarism: taming nature in Frederick the Great's Prussia. In: MAUCH, C. Nature in German history. New York: Berghahn, 2004. p. 10-30. 
CAMPANILI, M.; SCHAFFER, W. B. (Org.). Mata Atlântica: patrimônio nacional dos brasileiros. Brasília: Ministério do Meio Ambiente, 2010.

CARVALHO, M. M. X.; NODARI, E. S.; NODARI, R. O. Avanço no uso de agrotóxicos e das intoxicações humanas em Santa Catarina. Revista Brasileira de Agroecologia, Curitiba, v. 4, p. 2762-2766, 2009.

CRUTZEN, P. J.; STEFFEN, W. How long have we been in the Anthropocene era? Climatic Change, [S. 1.], n. 61, p. 251-257, 2003.

DUARTE, G. M. Depósitos Cenozoicos costeiros e a morfologia do extremo sul de Santa Catarina. Tese (Doutorado em Geologia Sedimentar) Instituto de Geociências, Universidade de São Paulo, São Paulo, 1993.

HADLICH, G. M. et al. Caracterização do meio rural em Sombrio. In: HADLICH, G. M.; SCHEIBE, L. F.; PELLERIN, J. Qualidade ambiental de municípios de Santa Catarina: o município de Sombrio. Florianópolis: Fepema, 1997. p. 61-93.

HERRMANN, M. L. de P. (Org.). Atlas de desastres naturais do estado de Santa Catarina. Florianópolis: Ioesc, 2005.

IBGE. INSTITUTO BRASILEIRO DE GEOGRAFIA E ESTATÍSTICA. Censo Agropecuário de 1975. Rio de Janeiro: IBGE, 1976.

Censo Agropecuário de 1985. Rio de Janeiro: IBGE, 1986.

. Censo Agropecuário de 1995. Rio de Janeiro: IBGE, 1996.

. Censo Demográfico 2010. Rio de Janeiro: IBGE, 2010. Disponível em: <http:/ /www. censo2010.ibge.gov.br>. Acesso em: 30 out. 2014.

KLANOVICZ, Jó. História ambiental e desastres: encontros entre política, tecnologia e sociedade. História Unisinos, São Leopoldo, v. 17, 2013, p. 293-302.
KLEVESTON, R. Efetividade do procedimento classificatório na avaliação da relação de uso e manejo das terras. Dissertação (Mestrado em Agroecossistemas) - Centro de Ciências Agrárias, Universidade Federal de Santa Catarina, Florianópolis, 1997.

LEINFELDER, R. Assuming responsibility for the Anthropocene: challenges and opportunities in education. In: TRISCHLER, H. Anthropocene: Envisioning the future of the Age of Humans. Munich: RCC Perspectives, 2013. p. 9-28.

MAIA, A. C. N.; SEDREZ, L. F. Narrativas de um dilúvio carioca: memória e natureza na grande enchente de 1966. História Oral, Rio de Janeiro, v. 2, p. 221-254, 2011.

MAUCH, C. Introduction. In: MAUCH, C.; PFISTER, C. (Org.). Natural disasters, cultural responses: case studies toward a global environmental history. Plymouth: Lexington Books, 2009. p. 1-17.

MAZOYER, M; ROUDART, L. História das agriculturas no mundo: do Neolítico à crise contemporânea. São Paulo: Unesp; Brasília: Nead, 2010.

MONTEIRO, M. A. Dinâmica atmosférica e a caracterização dos tipos de tempo na Bacia Hidrográfica do Rio Araranguá. Tese (Doutorado em Geografia) - Centro de Filosofia e Ciências Humanas, Universidade Federal de Santa Catarina, Florianópolis, 2007.

OLIVEIRA, Márcio Mauro. As circunstâncias da criação da extensão rural no Brasil. Cadernos de Ciência E Tecnologia, Brasília, v. 16, p. 97-134, maio/ago. 1999.

OLIVER-SMITH, A. What is a disaster: anthropological perspectives on a persistent question. In: OLIVER-SMITH, A.; HOFFMAN S. M. (Org.). The angry Earth: disaster in anthropological perspective. London: Routledge, 1999. p. 18-34. 
PÁDUA, J. A. As bases teóricas da história ambiental. Estudos Avançados, São Paulo, v. 24, n. 68, p. 81-101, 2010.

PORTELLI, M. E. Cartografia das alterações em depósitos de leques aluviais com base para uma estratigrafia relativa: Bacias dos rios Amola Faca e Rocinha, Timbé do Sul, SC. Dissertação (Mestrado em Geografia) - Centro de Filosofia e Ciências Humanas, Universidade Federal de Santa Catarina, Florianópolis, 1998.

PRESA, J. B. O arroz no espigão e o milho no banhado: programa PROVÁRZEAS - o desenvolvimento de uma política pública e o cultivo do arroz em municípios da bacia do Rio Araranguá. Dissertação (Mestrado em História) - Centro de Filosofia e Ciências Humanas, Universidade Federal de Santa Catarina, Florianópolis, 2011.

ROSSO, J. C. Avaliação do consumo de água em lavouras de arroz irrigado no sistema pré-germinado nas condições climáticas do sul catarinense. Dissertação (Mestrado em Ciências Ambientais) - Programa de Pós-Graduação em Ciências Ambientais, Universidade do Extremo Sul Catarinense, Criciúma, 2007.

SEDREZ, L. Desastres socioambientais, políticas públicas e memória. In: NODARI, E. S.; CORREA, S. M. de S. Migrações e natureza. São Leopoldo: Oikos, 2013. p. 185-202.

SELAU, M. da S. A ocupação do território Xokleng pelos imigrantes italianos no sul catarinense (1875-1925): resistência e extermínio. Dissertação (Mestrado em História) - Centro de Filosofia e Ciências Humanas, Universidade Federal de Santa Catarina, Florianópolis, 2006.

VIBRANS, A. C. et al. Extensão original e remanescentes da Floresta Ombrófila Densa em Santa Catarina. In: VIBRANS, A. C. et al. (Ed). Inventário florístico florestal de Santa Catarina. Blumenau: EdFURB, 2013. v. IV. p. 25-36. 